Check for updates

Cite this: Anal. Methods, 2018, 10, 1431

\title{
Determination of amphetamine-type stimulants (ATSs) and synthetic cathinones in urine using solid phase micro-extraction fibre tips and gas chromatography-mass spectrometry
}

\begin{abstract}
Khalid A. Alsenedi (iD *a and Calum Morrison (D) *b
In recent years, an increasing number of stimulant drugs and new psychoactive substances (NPSs) have caused concern in scientific communities and therefore innovative methods to extract compounds from complex biological samples are required. This work is aimed at developing and validating a clean, convenient and straightforward extraction procedure with microliter amounts of organic solvent using Solid Phase Micro-Extraction tips (SPME tips) and analysis using Gas Chromatography-Mass Spectrometry (GC-MS) in human urine samples. Another aim is to evaluate three different types of SPME fibre tips C18, C18-SCX (mixed mode) and PDMS-DVB. The quantification method examined the different classes of stimulant compounds included Amphetamine-Type Stimulants (ATSs) (amphetamine, methamphetamine, para-methoxyamphetamine (PMA), and ( \pm )-3,4-methylenedioxymethamphetamine (MDMA)) and synthetic cathinones (mephedrone, buphedrine (buphedrone ephedrine metabolite), 4methylephedrine (mephedrone metabolite), and pentylone). The method was developed with respect to several areas of the experimental design including $\mathrm{pH}$, ionic strength, addition of salts, vial dimensions, analytes and derivatisation, type of solvents, solvent volume, extraction and desorption time, agitation speeds in the extraction and desorption steps and matrix volume. The optimised method was validated for eight compounds using the SPME PDMS/DVB fibre tips with satisfactory linearity and selectivity ranging between 50 and $2000 \mathrm{ng} \mathrm{mL}^{-1}$, and limits of detection (LODs) and low limits of quantification (LLOQs) ranging between (5-25) and (25-100) $\mathrm{ng} \mathrm{mL}^{-1}$ respectively. Within-run and between-run accuracy and precision were $<15 \%$. The method was applied to real human urine samples indicating its suitability for common stimulant drugs and provided clean chromatograms with no interfering peaks. The assessment of green analytical chemistry for the method used was discussed and compared with Solid Phase Extraction (SPE). According to the results obtained we recommend the method for use in routine laboratories carrying out drug/forensic analysis for confirmation tests of the studied compounds.
\end{abstract}

Received 8th January 2018

Accepted 10th February 2018

DOI: $10.1039 /$ c8ay00041g

rsc.li/methods

\section{Introduction}

Over the past few years, approximately one compound has entered the recreational drug market on a weekly basis within the category of new psychoactive substances (NPSs). These are synthesised to bypass regulations and laws, and to have similar or stronger effects than existing drugs. Throughout the world, amphetamine-type stimulants (ATSs) are the second most commonly used drugs and often exceed heroin and cocaine use. ${ }^{\mathbf{1 - 3}}$

Synthetic cathinones covered approximately $23 \%$ of the global trends of individual NPSs reported in the Early Warning

${ }^{a}$ Forensic Medicine and Science, School of Medicine, Dentistry and Nursing, College of Medical, Veterinary and Life Sciences, University of Glasgow, Glasgow, G12 8QQ, UK. E-mail: khalidsenedi@gmail.com

${ }^{b}$ Forensic Medicine and Science, School of Medicine, Dentistry and Nursing, College of Medical, Veterinary and Life Sciences, University of Glasgow, Glasgow, G12 8QQ, UK. E-mail: calum.morrison@glasgow.ac.uk
Advisory (EWA) from 2008 to $2015 .{ }^{3}$ Cathinone is found in the plant Catha edulis (khat) and synthesized derivatives have a varied range of $\beta$-ketoamphetamines and have been sold as alternatives to ATSs. Fatalities and toxicity related to the abuse of stimulant drugs and synthetic cathinones are of international concern with several deaths reported..$^{\mathbf{4 - 1 1}}$

Consequently, the proof of identity of ATSs and synthetic cathinones in biological specimens is vital in the clinical, forensic and toxicology fields since most of the NPSs are not fully detected using routine immunoassay screening methods. This may be a result of cost-ineffectiveness or unavailability of reagents. Moreover, the confirmation of positive results in chromatographic and mass spectrometric techniques is required for accurate molecule identification and to distinguish between isomers and structures.

Biological samples contain various components with urine and blood which are not compatible with complex instrumentation. 
This can be solved by using a sample preparation technique which eliminates some components in biological samples and keeps the analytes of interest. Therefore, the requirement for a fast, clean and convenient procedure to reduce instrument contamination plays an essential role in any laboratory.

Solid Phase Micro-Extraction (SPME) was used for the first time in 1989 by Pawliszyn and his colleagues. ${ }^{12}$ It was carried out to minimise the time taken for the sample preparation and reduce the amount of both solvents and samples on the micro-liter scale. ${ }^{12}$ SPME is easy to employ, allows rapid screening with minimum contact with toxic solvents, and can be both manual or automated. It is a sensitive, efficient technique and reduces the time required and cost. It is highly efficient for screening purposes due to its speed and ease of use. The problem of sample loss, contamination and dilution can be avoided by the use of this technique. ${ }^{13}$

GC-MS is the most common technique in clinical toxicology and forensic laboratories and is more economical than LC-MSMS, and therefore methods developed using GC-MS have an extensive range of applicability in forensic toxicology laboratories.

The aims of this work were:

- To develop and validate a clean and convenient method on a microliter scale using SPME tips and GC-MS for the analysis of 8 stimulant drugs including ATSs and synthetic cathinones in urine, and the compounds studied are shown in Table 1.

- To evaluate the new biocompatible SPME LC tips containing fibres of C18, C18/SCX and PDMS/DVB.

- To reduce the environmental and health impacts compared to traditional sample preparation methods such as solid phase extraction (SPE).

- To address the need for green analytical chemistry.

- To evaluate this method when it is applied for real human urine samples.

\section{Materials and methods}

\section{Materials}

The reference standards of amphetamine, methamphetamine, PMA, MDMA, cathinone, mephedrone, buphedrine, 4-methylephedrine, and pentylone, three internal standards (ISDs) - amphetamine-d11 $\left(1 \mu \mathrm{g} \mathrm{mL} \mathrm{L}^{-1}\right)$, cathinone $\mathrm{d} 5\left(0.1 \mu \mathrm{g} \mathrm{mL} \mathrm{m}^{-1}\right)$ and pentylone-d3 $\left(0.1 \mu \mathrm{g} \mathrm{mL} \mathrm{m}^{-1}\right)$ as hydrochloride salts, pentafluoropropionic anhydride (PFPA), formic acid (FA), three types of SPME fiber tips: PDMS-DVB, C18 and C18-SCX silica, vial kits of two sizes, $0.3 \mathrm{~mL}$ and $1.2 \mathrm{~mL}$, natural PTFE/silicone septa (with slit), and thread $9 \mathrm{~mm}$ were purchased from Sigma-Aldrich, Gillingham, UK. The SPME fibre tips with stationary phase C18-SCX were kindly donated by Sigma Aldrich.

Methanol (MeOH), acetonitrile, ethyl acetate (EtOAc), acetone, 2-propanol, ammonium hydroxide $\left(\mathrm{NH}_{4} \mathrm{OH}\right)$, sodium phosphate dibasic, sodium chloride, sodium phosphate monobasic, dichloromethane (DCM), isopropanol (IPA), hydrogen chloride $(\mathrm{HCl})$, acetic acid, sodium hydroxide $(\mathrm{NaOH})$, sodium chloride $(\mathrm{NaCl})$ and microcentrifuge Eppendorf tubes $1.5 \mathrm{~mL}$ were obtained from VWR International, East Grinstead, UK.

Phosphate buffer and sodium phosphate were purchased from Fisher Scientific, Loughborough, UK. $200 \mu \mathrm{g}$ solid phase extraction (SPE) clean screen extraction columns, United Chemical Technologies (UCT), part number ZSDAU20, were purchased from Chromatography Direct, Runcorn, UK.

Deionised water was generated from an ultrapure water purification system (Merck Direct QR 3UV water deionizer).

\section{Ethics statement}

Written informed consent was obtained from all subjects. The protocol was reviewed and approved by the MVLS College Ethics Committee, University of Glasgow (200160055) and the Research Committee at Security Forces Hospital, Riyadh, Saudi Arabia (16-190-24).

Drug-Free Urine (DFU) specimens were collected from volunteers and confirmed negative for the target analytes. The protocol was reviewed and approved by the MVLS College Ethics Committee, University of Glasgow (200160020).

\section{Methods}

\section{Preparation of standards}

Stock solutions $\left(100 \mu \mathrm{g} \mathrm{mL} \mathrm{m}^{-1}\right)$ of the eight drugs, listed in Table 1 , were prepared by the dilution of purchased standards via

Table 1 Chemical structures

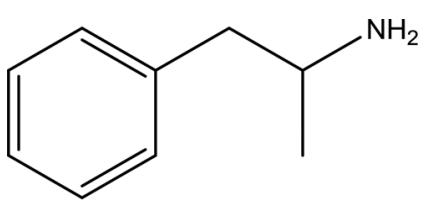

Amphetamine<smiles>CNC(C)Cc1ccccc1</smiles>

Methamphetamine<smiles>CNC(C)C(=O)c1ccc(C)cc1</smiles>

Mephedrone

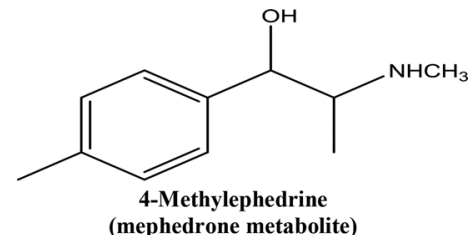<smiles>CCCC(NC)C(O)c1ccccc1</smiles>

Buphedrone ephedrine metabolite<smiles>CCCC(NC)C(=O)c1ccc2c(c1)OCO2</smiles> 
$1: 10$ dilution in methanol. A mixture of the working solution of each standard was prepared by the dilution of the $100 \mu \mathrm{g} \mathrm{mL}^{-1}$ stock solutions via 1 : 50 dilution in Drug-Free Urine (DFU) to reach a concentration of $2 \mu \mathrm{g} \mathrm{mL} \mathrm{m}^{-1}$.

Working internal standards (ISDs) of the deuterated standards were prepared by the dilution of purchased internal standards via 1 : 10 dilution in methanol to reach $10 \mu \mathrm{g} \mathrm{mL}^{-1}$. The mixture of the $8 \mathrm{drugs}$ in urine and ISDs were stored at $-20{ }^{\circ} \mathrm{C}$ until use.

\section{Optimised procedure}

The optimised procedure was applied to assess the parameters of the method validation work.

Initially, the SPME tips (PDMS-DVB fibre) were conditioned between 10 and 20 minutes in $\mathrm{MeOH}$ : distilled water $(50: 50)$.

$1 \mathrm{~mL}$ of the drug mixture in urine (for example $2 \mu \mathrm{g} \mathrm{mL}{ }^{-1}$ ) and $100 \mu \mathrm{L}$ of ISDs of amphetamine d11 and pentylone d5 $\left(1 \mu \mathrm{g} \mathrm{mL}^{-1}\right.$ ) with $0.5 \mathrm{~g} \mathrm{NaCl}$ and $100 \mu \mathrm{L}$ of $10 \% \mathrm{NaOH}(\mathrm{pH} 12.6)$ were added to $1.5 \mathrm{~mL}$ microcentrifuge Eppendorf tubes. The Eppendorf tubes were pierced before inserting the SPME tips.

The samples including tips were placed in a shaker (IKA VIBRAX VXR) for agitation at a speed of $2000 \mathrm{rpm}$. They were left for at least 1 hour so that equilibrium between the analytes and stationary phase was reached.

The SPME tips were transferred to $0.3 \mathrm{~mL}$ vials with the addition of $65 \mu \mathrm{L}$ of $\mathrm{MeOH}$ and left for 10 minutes at an agitation speed of $2000 \mathrm{rpm} .10 \mu \mathrm{L}$ of acidified methanol (1:9) was added, and the vials were evaporated under a stream of nitrogen at room temperature (RT) until fully dry.

The vials were then derivatised by adding $50 \mu \mathrm{L}$ PFPA and EtOAc $(2: 1)$. The samples were capped and vortexed immediately for 3-5 seconds and then incubated for 10-15 minutes at $60{ }^{\circ} \mathrm{C}$. The samples were evaporated under a stream of nitrogen at RT. The time required until fully dried in the evaporation steps was 2-5 minutes only. The samples were reconstituted in $50 \mu \mathrm{L}$ of ethyl acetate before $1 \mu \mathrm{L}$ was injected into the GCMS for analysis (see Fig. 1).

\section{Method development preparation}

The method development of SPME tips was assessed based on the following criteria: the pH of buffer, ionic strength, addition of salts, size of vials, analyte and derivatisation, type of solvents, solvent volume, extraction time, agitation speed in the extraction step, desorption time, agitation speed in the desorption step and matrix volume. Each criterion was evaluated as a single factor keeping the other factors constant.

The parameters were assessed based on the absolute recovery ${ }^{\mathbf{1 4}}$ by adding $1 \mathrm{~mL}$ urine containing the mixture of the 8 drugs $\left(1 \mu \mathrm{g} \mathrm{mL} \mathrm{mL}^{-1}\right)$. A $50 \mu \mathrm{L}$ ISD $\left(0.5 \mu \mathrm{g} \mathrm{mL}^{-1}\right)$ of amphetamine d11 was added prior to the evaporation step.

$100 \mu \mathrm{L}$ of a duplicate unextracted mixture of the 8 drug samples $\left(1 \mu \mathrm{g} \mathrm{mL}^{-1}\right)$ and a $50 \mu \mathrm{L}$ ISD of amphetamine d11 $\left(0.5 \mu \mathrm{g} \mathrm{mL}{ }^{-1}\right)$ were added on each evaluation day.

The response of extracted (response of extracted analyte response of ISD)/response of unextracted (response of unextracted analyte - response of ISD) ratio (\%) is calculated as the recovery rate on each day of the method development process.

The pH buffering of urine was evaluated on the three fibres and adjusted to $\mathrm{pH} \mathrm{3,5,} \mathrm{7,} 9$ and 11 by adding small drops of formic acid, $\mathrm{HCl}$ for acidity products, $25 \% \mathrm{NaOH}$ for alkaline products and phosphate buffer for $\mathrm{pH} 7$.

The ionic strength and the additive of $\mathrm{NaOH}$ and $\mathrm{KOH}$ salts $(5 \%, 10 \%$ and $25 \%(\mathrm{w} / \mathrm{v}))$ with and without $\mathrm{NaCl}(0.1,0.25,0.5$, 0.75 and $1 \mathrm{~g} ; 5 \%, 10 \%$ and $25 \%(\mathrm{w} / \mathrm{v}))$ were examined in duplicate samples. The experiments were repeated three times on three different days for $\mathrm{NaOH}(5 \%, 10 \%$ and $25 \%)$ with $\mathrm{NaCl}$ $(0.1,0.25,0.5,0.75$ and $1 \mathrm{~g})$ to confirm the results.

The evaluation of the sample volume was performed in triplicate vials at volumes of 1000,500 and $100 \mu \mathrm{L}$ at a concentration of $1 \mu \mathrm{g} \mathrm{mL} \mathrm{m}^{-1}$.

The derivatisation agent was evaluated by the application of the duplicate samples of PFPA derivatives added pre-, during and post-extraction and after the first evaporation step.

The solvents $\mathrm{MeOH}$, acetonitrile, EtOAc, $\left(\mathrm{NH}_{4} \mathrm{OH}: \mathrm{MeOH}\right.$; $2: 98), \quad\left(\mathrm{NH}_{4} \mathrm{OH}: \mathrm{MeOH} ; \quad 0.5: 99.5\right), \quad\left(\mathrm{DCM}: \mathrm{IPA}: \mathrm{NaOH}_{4}\right.$;

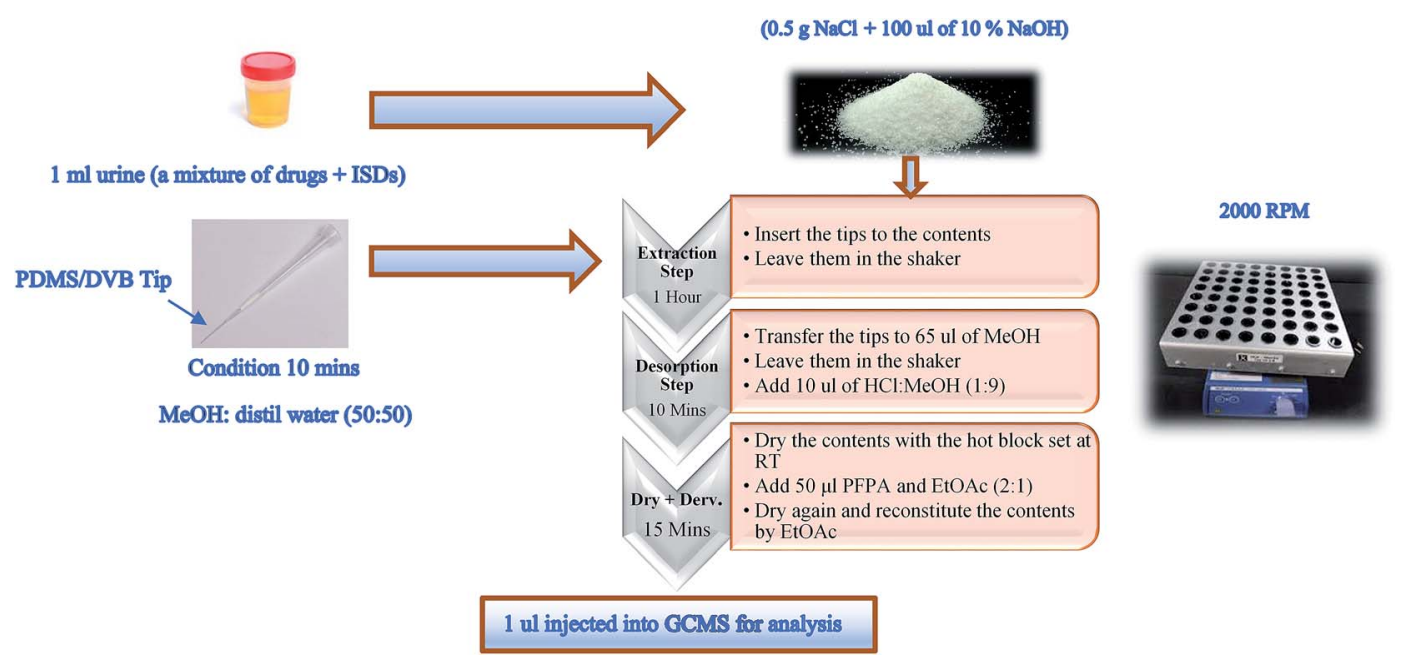

Fig. 1 Illustration of the optimum condition procedure applied to SPME PDMS/DVB fibre tips in the mixture of drugs in urine samples. 
$78: 20: 2$ ), IPA and (acetone : water; $20: 80$ ) were evaluated in triplicate samples on two days.

The triplicate samples at extraction times of 15, 30, 45, 60, 90 and 120 min with agitation speeds of 500, 1000, 1500 and $2000 \mathrm{rpm}$ were evaluated on two days.

The triplicate samples in the desorption step at times of 15, 30, 45, 60 and $90 \mathrm{~min}$ with agitation speeds of 500, 1000, 1500 and $2000 \mathrm{rpm}$ were assessed. The triplicate samples in the desorption step were evaluated again at times of 20, 30, 40 and 50 min with agitation speeds of 1500 and $2000 \mathrm{rpm}$. The triplicate samples in the desorption step were evaluated once more at times of 1, 5, 10 and $20 \mathrm{~min}$ at an agitation speed of $2000 \mathrm{rpm}$.

The evaluation of two types of vials, Eppendorf vials $(1.5 \mathrm{~mL})$ and kit vials $(1.2 \mathrm{~mL})$, was performed by applying the optimum procedure in duplicate samples. They were examined once more to evaluate the linearity at concentrations of 50, 100, 250, 500, 750,1000 , and $2000 \mathrm{ng} \mathrm{mL}{ }^{-1}$ (duplicate samples at each point). All the developed method parameters were tested in the spiked urine containing the 8 stimulant drugs at a concentration of $1 \mu \mathrm{g} \mathrm{mL}{ }^{-1}$.

\section{Method validation}

The method was validated through evaluating the method validation parameters based on the Scientific Working Group for Forensic Toxicology (SWGTOX, 2012) guidelines: linearity, limit of detection (LOD), lower limit of quantitation (LLOQ), accuracy, precision, selectivity, interference and carryover.

The linearity study was performed for each substance by spiking $1 \mathrm{~mL}$ of drug-free urine (DFU) with the mixture of standards to obtain the concentrations of 50, 100, 250, 500, 750, 1000 , and $2000 \mathrm{ng} \mathrm{mL}^{-1}$. Calibration curves for the mixtures in urine were plotted by the linearity method to calculate the linear regression $\left(R^{2}\right)$ of the area ratio of each compound with the ISDs versus the concentration of the analyte. It was assessed by analysing 20 separate calibration curves on five consecutive days. The accuracy of each point was calculated in the linearity study and should not exceed $20 \%$.

The limit of detection (LOD) and the lower limit of quantitation (LLOQ) were defined as a signal-to-noise $(\mathrm{S} / \mathrm{N})$ ratio exceeding three and ten respectively which were assessed for at least three ions of each substance. The assessment of the mixtures of the urine samples was repeated for each concentration ten times at concentrations of 200, 100, 50, 25, 10, 5, and $1 \mathrm{ng} \mathrm{mL}^{-1}$. The LLOQ parameter was assessed once more by calculating the lowest concentration at which the analyte could be quantified (relative standard deviation (RSD) and bias $\leq 20 \%$ ).

The accuracy and precision of the method were determined by the analysis of four replicate samples at three quality controls (QC): $\mathrm{QC}_{1}=250, \mathrm{QC}_{2}=850$ and $\mathrm{QC}_{3}=1500 \mathrm{ng} \mathrm{mL}^{-1}$ on the same days of the linearity study. Within-run and between-run accuracy and precision were determined for each analyte with the maximum of RSD and bias values not exceeding $15 \%$.

The interference study was performed by analysing ten different individual blank urine samples for verifying the absence of the peaks interfering with the analytes of interest via SIM mode.
The selectivity of the method was assessed by running triplicate mixture samples of 22 similar drugs cathinone, methcathinone, flephedrone, 4-methyl- $N$-ethyl-norephedrine (4-MEC metabolite), bupherone, $N$-ethylecathinone, para-methoxyamphetamine (PMA), pentedrone, methedrone, methylone, butylone, ethylone, pyrovalerone, 3,4-methylenedioxyamphetamine (MDA), para-methoxy- $N$-methylamphetamine (PMMA), 4ethylmethylcathinone (4-EMC), methedrone, ( \pm )- $N$-ethyl-3,4methylenedioxyamphetamine (MDEA), $\alpha$-pyrrolidinovalerophenone ( $\alpha$-PVP), $3^{\prime}, 4^{\prime}$-methylenedioxy- $\alpha$-pyrrolidinopropiophenone (MDPPP), naphyrone, and methylenedioxypyrovalerone (MDPV) at a concentration of $2 \mu \mathrm{g} \mathrm{mL}{ }^{-1}$ spiked with DFU.

Carryover effects were checked by analysing blank urine specimens after the injection of the highest point of the calibrator.

All method validation parameters were obtained by applying the optimised procedure mentioned above (see the Optimised procedure section; Fig. 1).

\section{Application to real urine samples}

The method was applied to three urine samples collected from Saudi Arabia that were confirmed positive for cathinone when previously analysed with a valid solid phase extraction method (SPE). The SPE method was validated in our laboratory for the determination of 20 stimulant drugs based on GC-mass spectrometry.

\section{Fragmentation criteria}

The criteria for the identification of the mixture compounds were the retention time $\left(t_{\mathrm{R}}\right)$ with the presence of at least three fragmentation ions and their relative ion intensities\%. For the identification of an analyte, $t_{\mathrm{R}}$ should not vary more than $\pm 1 \%$; relative ion intensities should not exceed more than $\pm 10 \%$ for ions with relative intensities $>50 \%$.

\section{GC-MS methodology}

The method was carried out with Gas Chromatography-Mass Spectrometry (GC-MS) using a 7890A GC/5975C MSD, a split/ splitless inlet and a DB-5ms (5\% phenyl/95\% methylpolysiloxane; $30 \mathrm{~m} \times 0.25 \mathrm{~mm}, 0.25 \mu \mathrm{m}$ film thickness) separation column (all from Agilent Technologies, Waldbronn, Germany). Helium was used as a carrier gas (99.99\% purity). Splitless injection at $225{ }^{\circ} \mathrm{C}$ was employed. The column temperature programme was initially started at $70{ }^{\circ} \mathrm{C}$ and then raised to $200{ }^{\circ} \mathrm{C}$ at a rate of $11^{\circ} \mathrm{C} \mathrm{min}^{-1}$ (held for 4 minutes), and $200{ }^{\circ} \mathrm{C}$ to $280{ }^{\circ} \mathrm{C}$ at a rate of $10^{\circ} \mathrm{C} \mathrm{min}{ }^{-1}$ (held for 1 minute). The total time was 25 minutes. The MS transfer line temperature was kept at $250{ }^{\circ} \mathrm{C}$. The MS was operated in the electron impact ionisation mode $(70 \mathrm{eV})$. The ion source was maintained at $200{ }^{\circ} \mathrm{C}$. MS data acquisition was initiated at 7 minutes and was performed in the selected ion monitoring (SIM) mode. The method was developed to provide an excellent separation and response. All data acquisition and processing steps were performed using GC/MSD ChemStation Software Version 6.5. 


\section{Results and discussion}

\section{SPME tip extraction and GC-MS methods}

GC MS was initially developed until the desired responses were achieved along with separation and detection by applying the mixture of the 8 stimulant drugs. Each standard of the mixture compounds was prepared alone by running unextracted samples with PFPA derivatives. The separation, $t_{\mathrm{R}}$ and fragmentation patterns with the ion intensity ratio\% were considered and recorded. The random procedure of SPME tips was initially applied to the optimised conditions of the GC MS. The responses of the SMPE tips were compared with unextracted
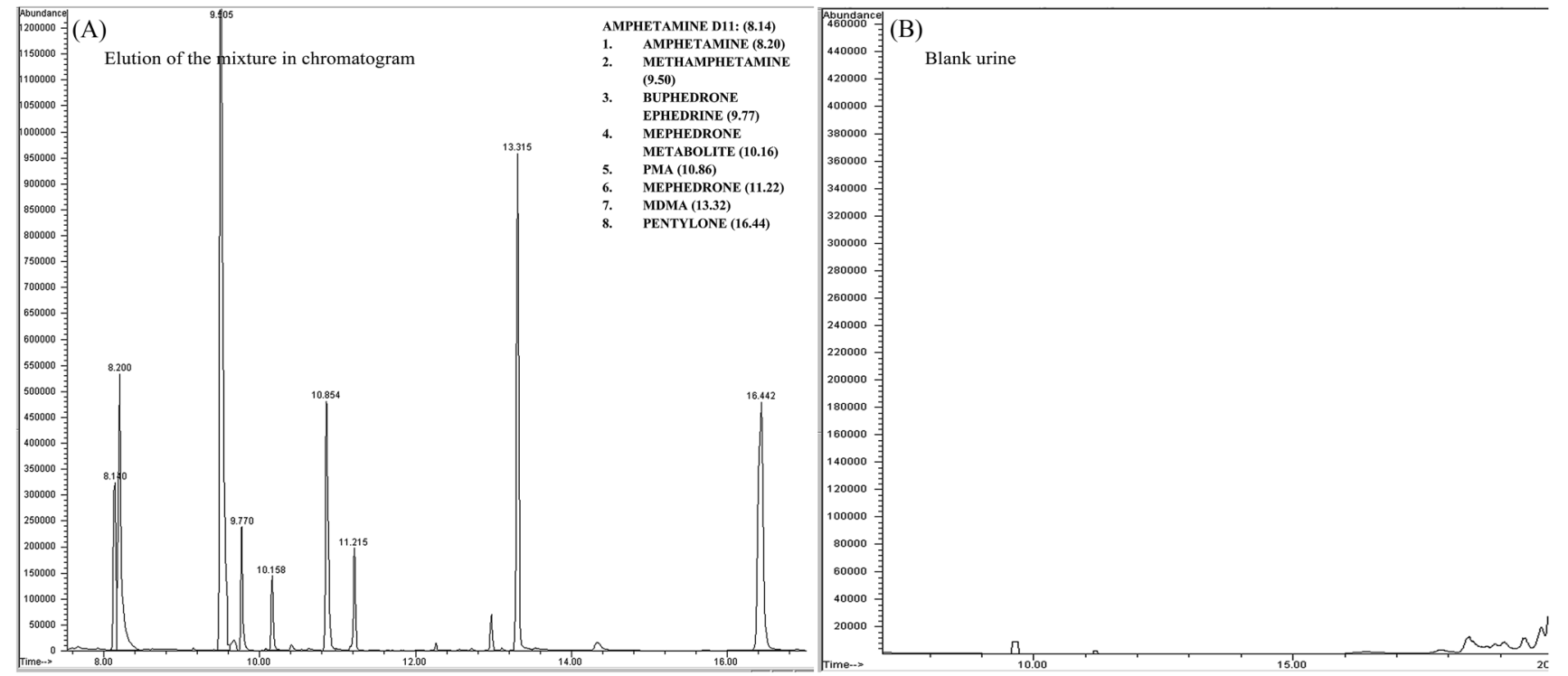

Fig. 2 (A) SIM chromatogram for the eight stimulant drugs (SPME tips and PFPA derivative; optimum conditions were applied) at a concentration of $1 \mu \mathrm{g} \mathrm{mL} \mathrm{m}^{-1}$ in a urine sample. (B) Chromatogram (SIM) for a blank urine sample.

Table 2 SIM fragmentation patterns $(\mathrm{m} / \mathrm{z})$ and relative ion intensities (ratio\%) with the retention time $\left(t_{R}\right)$. Quantification ions in bold. The remaining ions were used as qualifier ions with the ratio (\%)

\begin{tabular}{|c|c|c|c|c|c|c|c|}
\hline Target compounds & $t_{\mathrm{R}}$ & $m / z$ & Ratio (\%) & Target compounds & $t_{\mathrm{R}}$ & $m / z$ & Ratio (\%) \\
\hline \multirow[t]{4}{*}{ Amphetamine d11 } & 8.422 & 194 & 100 & \multirow{4}{*}{$\begin{array}{l}\text { 4-Methylephedrine } \\
\text { (mephedrone metabolite) }\end{array}$} & \multirow[t]{4}{*}{10.158} & 204 & 100 \\
\hline & & 128 & 72 & & & 119 & 13 \\
\hline & & 98 & 33 & & & 160 & 20 \\
\hline & & & & & & 308 & 3 \\
\hline \multirow[t]{4}{*}{ Amphetamine } & 8.486 & 190 & 100 & \multirow[t]{4}{*}{ PMA } & \multirow[t]{4}{*}{10.854} & 121 & 100 \\
\hline & & 118 & 79 & & & 148 & 42 \\
\hline & & 91 & 36 & & & 190 & 5 \\
\hline & & 65 & 9 & & & 311 & 7 \\
\hline \multirow[t]{4}{*}{ Methamphetamine } & 9.505 & 204 & 100 & \multirow[t]{4}{*}{ Mephedrone } & \multirow[t]{4}{*}{11.215} & 119 & 100 \\
\hline & & 160 & 31 & & & 204 & 25 \\
\hline & & 118 & 24 & & & 91 & 20 \\
\hline & & 91 & 14 & & & 160 & 14 \\
\hline \multirow[t]{4}{*}{ Pentylone d5 } & 16.339 & 193 & 100 & \multirow[t]{4}{*}{ MDMA } & \multirow[t]{4}{*}{13.315} & 204 & 100 \\
\hline & & 235 & 86 & & & 162 & 73 \\
\hline & & 148 & 380 & & & 135 & 43 \\
\hline & & & & & & 339 & 12 \\
\hline \multirow[t]{4}{*}{ Buphedrine (buphedrone metabolite) } & 9.770 & 218 & 100 & \multirow[t]{4}{*}{ Pentylone } & \multirow[t]{4}{*}{16.442} & 149 & 100 \\
\hline & & 119 & 12 & & & 190 & 22 \\
\hline & & 308 & 3 & & & 232 & 19 \\
\hline & & 160 & 18 & & & 381 & 5 \\
\hline
\end{tabular}


cathinones to provide excellent repeatability and reproducibility using only microliter quantities of organic solvent $(50 \mu \mathrm{L}$ of $\mathrm{MeOH})$. The advantage of using SPME PDMS/DVB fibre tips is that the equilibrium between the analyte and the stationary phase occurs in only one step. This provides safety and less handling of the operators. Furthermore, it benefits the environment and economy with less consumption of vials, solvents and chemicals making this procedure favourable.

Two types of vials were used in the procedure, the first one (1.5 mL Eppendorf vial) was used for the sample preparation and extraction steps. The second vial ( $0.3 \mathrm{~mL}$ kit vial) was used in the following stages: the desorption, evaporation, derivatisation and GC-MS stages. The extraction proficiency proved the validity of the method to extract and quantify the target analytes even at low sample volumes and concentrations. The total time required for the sample preparation process until running the samples was 2-3 hours (as an average of preparing 20-30 samples). The conditions of gas chromatography were adjusted to provide an excellent peak shape and responses which allow the separation of the 8 stimulant substances in 25 minutes by using PFPA derivatives. In addition, the conditions of chromatography also permitted the separation of two metabolites in urine (buphedrone ephedrine metabolite and mephedrone metabolite).

GC MS is commonly used in the majority of laboratories and is attractive in terms of financial sustainability.

The method was applied to the collected urine samples to demonstrate the validity of the technique for application as a confirmation method in forensic toxicology analysis.

The main aims of the method development were:

- To reach the highest equilibrium between the analyte and stationary phase in SPME tips.

- To obtain the highest recovery\%.

- To assess the three different fibre tips.

- To validate the SPME tips for the quantification of the 8 compounds in urine using GC MS.

The extraction products can be optimised by altering the sample conditions. ${ }^{15}$ Therefore, several parameters of

Table 3 Summary of the optimum conditions of the method development parameters. The outcome was concluded based on the most significant recovery\% of the 8 stimulant drugs at a concentration of $1 \mu \mathrm{g} \mathrm{mL} \mathrm{m}^{-1}$ in urine. Invalid (mentioned in the table) was concluded after the calculation of RSD and bias in each parameter

\begin{tabular}{|c|c|c|c|}
\hline Parameters versus fiber type & PDMS/DVB & C18 & Mixed mode \\
\hline Salts & $\mathrm{NaOH}+\mathrm{NaCl}$ & Formic acid & Formic acid + HCL \\
\hline Ionic strength (v/w) & $10 \% \mathrm{NaOH}+0.5 \mathrm{~g} \mathrm{NaCl}(\mathrm{pH} 12.6)$ & $100 \mu \mathrm{L}$ formic acid & $100 \mu \mathrm{L} \mathrm{pH} 3 \mathrm{FA}+100 \mu \mathrm{L} 0.1 \mathrm{HCL}$ \\
\hline $\mathrm{pH}$ & $\begin{array}{l}\geq 11 \text {, the greatest recovery results } \\
\text { were at } \mathrm{pH} 12.6\end{array}$ & pH 2.8 & pH 3.3 \\
\hline Sample volume & $1 \mathrm{~mL}$ & Invalid & Invalid \\
\hline Derivatisation agent (PFPA) & $\begin{array}{l}\text { When the PFPA was added after the } \\
\text { evaporation step }\end{array}$ & After the evaporation step & After the evaporation step \\
\hline Extraction time & $\geq 1$ hour & Invalid & Invalid \\
\hline Extraction speed & $2000 \mathrm{rpm}$ & Invalid & Invalid \\
\hline Desorption type & $\begin{array}{l}\text { MeOH, acetonitrile and DCM: ISO: } \\
\mathrm{NaOH}_{4}\end{array}$ & Invalid & Invalid \\
\hline Desorption time & $10 \mathrm{~min}$ & Invalid & Invalid \\
\hline Desorption speed & $2000 \mathrm{rpm}$ & Invalid & Invalid \\
\hline Linearity & $0.992-999$ & Invalid & Invalid \\
\hline Recovery & $2-80 \%$ & $0.1-10 \%$ & $0.1-10 \%$ \\
\hline Vial type & Both Eppendorf vials and kit vials & Invalid & Invalid \\
\hline
\end{tabular}
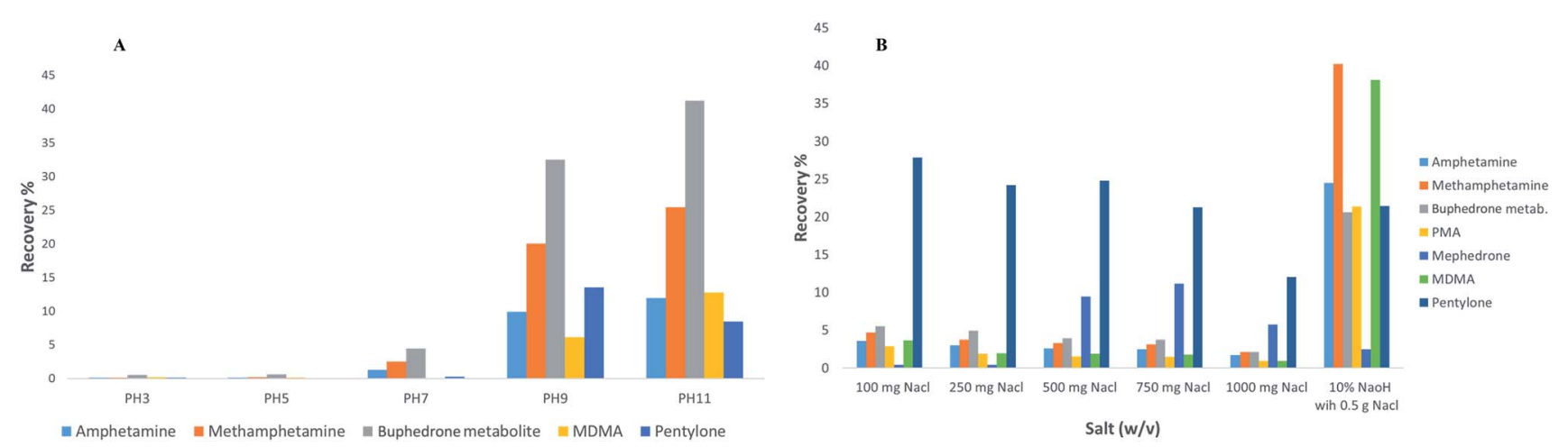

Fig. 3 An example of the developed method results for some compounds examined showing the effect of buffering $\mathrm{pH}$ (A) and the additive of salts (B); in SPME PDMS/DVB fibre tips (duplicate samples of the drug mixture at a concentration of $1 \mu \mathrm{g} \mathrm{m} L^{-1}$ in urine). 


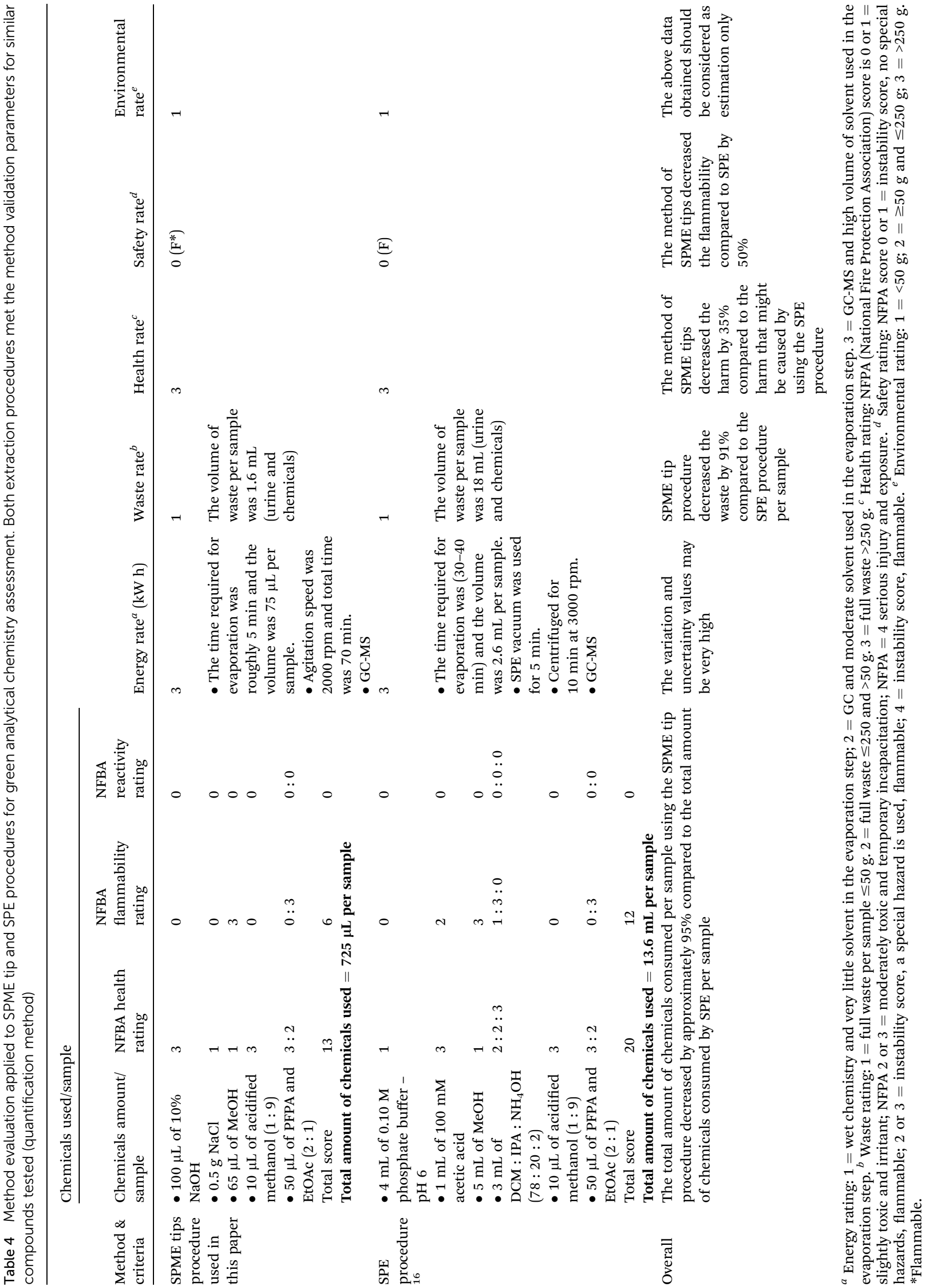


experimental design were considered in the process of the method development (the $\mathrm{pH}$ of buffer, ionic strength, addition of salts, size of vials, analyte and derivatisation, type of solvent, solvent volume, extraction time, agitation speed in the extraction step, desorption time, agitation speed in the desorption step and matrix volume). The work was carried out to study three different fibre tips (C18, C18-SCX and PDMS/DVB) via method development processes. The stationary phase of PDMS/ DVB fibre tips provided the maximum recovery (2-80\%) compared to C18 $(0.1-10 \%)$ and C18-SCX $(0.1-10 \%)$. The recovery was calculated through all the method development parameter processes.

The results of the developed method are summarised in Table 3. In summary, the PDMS/DVB fibre tips proved to reach the maximum equilibrium in the reaction for all stimulant drugs tested. An example of $\mathrm{pH}$ buffering results and addition of salts is shown in Fig. 3.

\section{Green analytical chemistry}

The assessment of green analytical chemistry is complex and has several criteria and variations that need to be checked. In many cases it is difficult to meet the ideal green analytical methodology in the procedure, because method validation is difficult to achieve without the use of hazardous substances. In our procedure, we minimise the use of solvents, chemicals and reagents to meet the lowest effects or hazards with the consideration of the criteria of assessment and method validation.

The five criteria for the evaluation of green analytical chemistry are health, safety, environment, energy and waste. Based on the above criteria, we compared the SPME tip procedure with the SPE method ${ }^{16}$ in the stage of sample preparation only, i.e. when they were applied for ATSs and synthetic cathinone compounds. Both extraction methods have similar compounds that meet the requirements of method validation. ${ }^{17-19}$ The tool of assessment was recently discussed in a paper by Płotka-Wasylka. ${ }^{20}$ For the results and overall discussion see Table 4.

\section{Method validation}

The results for all obtained validation parameters were successful for the observed analytes.

The method was linear demonstrated by $R^{2}$ which was always higher than 0.992 in the range of the LLOQ (at least $\geq 100 \mathrm{ng} \mathrm{mL}{ }^{-1}$ ) for all compounds of interest.

The LODs ranged from 5 to $25 \mathrm{ng} \mathrm{mL}^{-1}$ for all the drugs investigated.

The LLOQ ranged from 25 to $100 \mathrm{ng} \mathrm{mL}^{-1}$ for all the substances tested.

Both the within and between run precision and accuracy were satisfactory with results in an acceptable range giving values lower than $15 \%$.

No carryover was recognised for any of the stimulant analytes. No peak was observed from endogenous urine compounds in the blank for the interference study or from the 20 drugs tested in the selectivity study that affected the interpretation

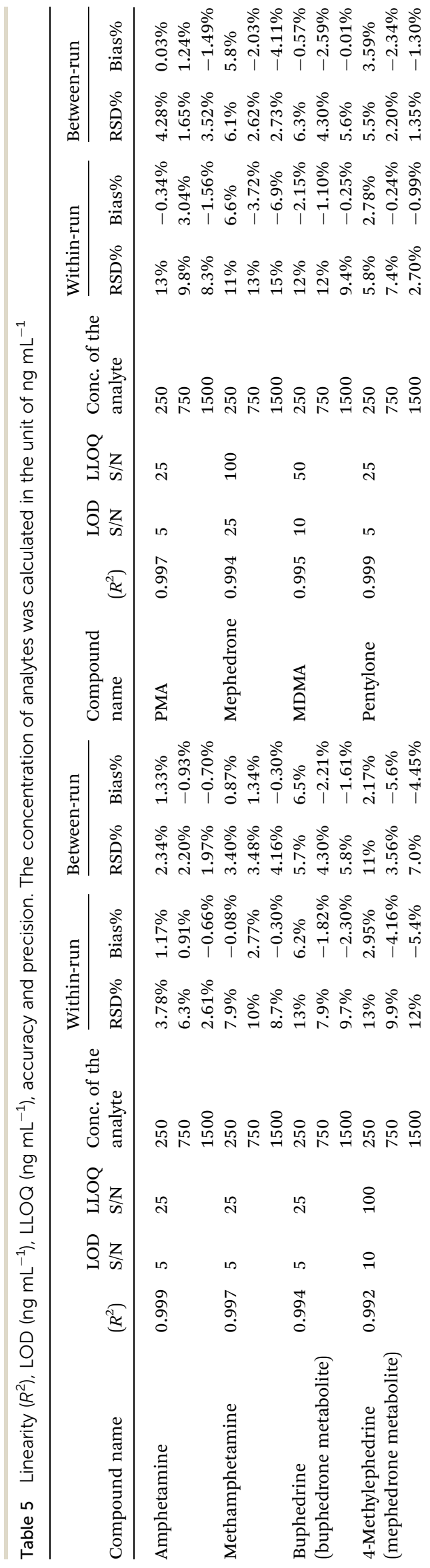


Table 6 The comparison of the results of three positives of cathinone in urine specimens when it's applied to SPE and SPME tips in GC MS (the urine samples were collected from real human cases in Saudi Arabia under the approval of the ethics committee). The unit of concentration is $\mathrm{ng} \mathrm{mL} \mathrm{m}^{-1}$. The results were obtained after plotting great linearity and QCs. The average of the concentration of triplicate samples was applied to each sample

Serial \&

extraction method type

Sample number 1

Sample number 2

Sample number 3
The average conc. for the

validated method of SPE with \pm SD

$802 \pm 32$

$1209 \pm 47$

$227 \pm 30$
The average conc. for the new trends of SPME PDMS/DVB fibre tips with \pm SD
$806 \pm 76$
$1201+98$
$285 \pm 51$

results in SIM mode. The outcome data to evaluate the method validation parameters are presented in Table 5 .

The SPME PDMS/DVB fiber tip method was applied to real human samples (three cases) to confirm three positives of cathinone. The confirmation results of SPME tips were compared with the confirmation results of the validated SPE method. The positive results obtained from the case samples prove the ability of the method for the quantification and qualification of similar drugs such as cathinone compounds. The repeatability and reproducibility of the method with excellent selectivity and sensitivity were successfully demonstrated in the detection of the specimens. See Table 6 for the results.

\section{Conclusion}

A clean, expedient, reliable and less costly procedure was developed and validated using urine samples for the determination of ATSs and cathinone groups. The method used minimum solvent to meet the requirements of green analytical chemistry with the evaluation of two procedures in the sample preparation stage. The final method included SPME fibre tips (PDMS/DVB) with a PFPA derivative providing an efficient extraction procedure followed by GC-MS analysis. The SPME fibre tip (PDMS/DVB) method can be used for the confirmation of eight substances with excellent repeatability and reproducibility. The sensitivity and selectivity of the technique were established for the determination and detection of the compounds concerned. The limits of quantitation were sufficient to quantify the positive of amphetamine, methamphetamine, PMA, MDMA, mephedrone, buphedrine, 4-methylephedrine and pentylone. The developed procedure delivers only one system to confirm the eight stimulant compounds including ATSs and designer cathinones in human urine specimens. Real urine case samples were applied for the confirmation test only. The specimens demonstrated the validity and the suitability of the method for routine analysis of toxicology forensic samples for the drugs mentioned and for the confirmation test only. The applicability of GC-MS in many laboratories worldwide enables this method to have the potential for widespread use.

\section{Conflicts of interest}

There are no conflicts to declare.

\section{Acknowledgements}

This work was gratefully supported by Forensic Medicine and Science, University of Glasgow, UK, and the Ministry of High Education of Saudi Arabia (I946). The authors would like to thank Dr Craig Aurand and Dr Denise Wallworth of Sigma Aldrich for the samples of SPME fibre tips.

\section{References}

1 EMCDDA, EU Drug Markets Report: In-depth Analysis, 2016 cited 2017, 21 November, http://www.emcdda.europa.eu/ system/files/publications/2373/TD0216072ENN.PDF.

2 UNODC, World Drug Report, 2016, https://www.unodc.org/ documents/scientific/

WORLD_DRUG_REPORT_2016_web.pdf.

3 UNODC, global smart update, 2016 cited 2017, 15 December, https://www.unodc.org/documents/scientific/Global-

SMARTUpdate-2016-vol-16.pdf.

$4 \mathrm{H}$. Torrance and G. Cooper, The detection of mephedrone (4methylmethcathinone) in 4 fatalities in Scotland, Forensic Sci. Int., 2010, 202(1), e62-e63.

5 P. D. Maskell, et al., Mephedrone (4-methylmethcathinone)related deaths, J. Anal. Toxicol., 2011, 35(3), 188-191.

6 K. J. Lusthof, et al., A case of extreme agitation and death after the use of mephedrone in The Netherlands, Forensic Sci. Int., 2011, 206(1), e93-e95.

7 B. K. Logan, et al., Recommendations for toxicological investigation of drug-impaired driving and motor vehicle fatalities, J. Anal. Toxicol., 2013, bkt059.

$8 \mathrm{~K}$. Liveri, et al., A fatal intoxication related to MDPV and pentedrone combined with antipsychotic and antidepressant substances in Cyprus, Forensic Sci. Int., 2016, 265, 160-165.

9 P. Kriikku, et al., New designer drug of abuse: 3,4methylenedioxypyrovalerone (MDPV). Findings from apprehended drivers in Finland, Forensic Sci. Int., 2011, 210(1), 195-200.

10 M. Wikström, et al., Two fatal intoxications with the new designer drug methedrone (4-methoxymethcathinone), $J$. Anal. Toxicol., 2010, 34(9), 594-598.

11 M. Sykutera, M. Cychowska and E. Bloch-Boguslawska, A fatal case of pentedrone and $\alpha$-pyrrolidinovalerophenone poisoning, J. Anal. Toxicol., 2015, 39(4), 324-329. 
12 R. P. Belardi and J. B. Pawliszyn, The application of chemically modified fused silica fibers in the extraction of organics from water matrix samples and their rapid transfer to capillary columns, Water Qual. Res. J. Can., 1989, 24(1), 179-191.

$13 \mathrm{H}$. Kataoka, Recent developments and applications of microextraction techniques in drug analysis, Anal. Bioanal. Chem., 2010, 396(1), 339-364.

$14 \mathrm{~W}$. Figg and H. L. McLeod, Handbook of Anticancer Pharmacokinetics and Pharmacodynamics, Springer Science \& Business Media, 2004.

15 G. Theodoridis, E. d. Koster and G. De Jong, Solid-phase microextraction for the analysis of biological samples, $J$. Chromatogr. B: Biomed. Sci. Appl., 2000, 745(1), 49-82.
16 K. A. Alsenedi and C. Morrison, Comparison of six derivatizing agents for the determination of nine synthetic cathinones using gas chromatography-mass spectrometry, Anal. Methods, 2017, 9(18), 2732-2743.

17 A. Gałuszka, et al., Analytical Eco-Scale for assessing the greenness of analytical procedures, TrAC, Trends Anal. Chem., 2012, 37, 61-72.

18 D. Raynie and J. L. Driver, Green assessment of Chemical Methods. In 13th Green Chem Conf., USA, 2009.

19 P. J. Dunn, The importance of green chemistry in process research and development, Chem. Soc. Rev., 2012, 41(4), 1452-1461.

$20 \mathrm{~J}$. Płotka-Wasylka, A new tool for the evaluation of the analytical procedure: Green Analytical Procedure Index, Talanta, 2018, 181, 204-209. 